\title{
Turf wars in radiology: what must academic radiology do?
}

\author{
Vijay M. Rao \\ Thomas Jefferson University \\ David C. Levin \\ HealthHelp, LLC., Houston, TX
}

Follow this and additional works at: https://jdc.jefferson.edu/radiologyfp

Part of the Radiology Commons

Let us know how access to this document benefits you

\section{Recommended Citation}

Rao, Vijay M. and Levin, David C., "Turf wars in radiology: what must academic radiology do?" (2007). Department of Radiology Faculty Papers. Paper 3.

https://jdc.jefferson.edu/radiologyfp/3

This Article is brought to you for free and open access by the Jefferson Digital Commons. The Jefferson Digital Commons is a service of Thomas Jefferson University's Center for Teaching and Learning (CTL). The Commons is a showcase for Jefferson books and journals, peer-reviewed scholarly publications, unique historical collections from the University archives, and teaching tools. The Jefferson Digital Commons allows researchers and interested readers anywhere in the world to learn about and keep up to date with Jefferson scholarship. This article has been accepted for inclusion in Department of Radiology Faculty Papers by an authorized administrator of the Jefferson Digital Commons. For more information, please contact: JeffersonDigitalCommons@jefferson.edu. 


\title{
TURF WARS IN RADIOLOGY: WHAT MUST ACADEMIC RADIOLOGY DO?
}

\author{
Vijay M. Rao, M.D. ${ }^{a}$ \\ David C. Levin, M.D. ${ }^{\text {a,b }}$
}

a. Department of Radiology, Thomas Jefferson University Hospital and Jefferson Medical College, Philadelphia, PA.

b. HealthHelp, LLC., Houston, TX

\author{
Communicating author: $\quad$ Vijay M. Rao, M.D. \\ Department of Radiology \\ Main 1087 \\ Thomas Jefferson University Hospital \\ Philadelphia, Pa. 19107 \\ Phone: 215-955-7264 \\ Fax: 215-955-6751 \\ Email: vijay.rao@jefferson.edu
}




\begin{abstract}
In a previous article in this series, we called upon private practice radiology groups to better support radiology research financially, but also pointed out that academic radiology must make some changes as well. In this article, we discuss those changes in detail. They include revising the structure of the radiology residency, changing the timing of the American Board of Radiology oral examinations, requiring that all residents receive research training, and emphasizing the value of clinical and translational research. The Society of Chairmen of Academic Radiology Departments (SCARD) needs to assume a leadership role in implementing these changes.
\end{abstract}

\title{
SUMMARY SENTENCE
}

The authors suggest some changes they feel the academic radiology community must make in order to help preserve the integrity of the field.

\section{KEY WORDS}

academic radiology

economics, medical

radiology research

radiology and radiologists, socioeconomic issues 
In a recent article in this series [1], we stressed that high quality research conducted by academic radiology departments was a critical element in pursuing turf wars in imaging. If radiologists fail to do leading edge research to advance the science of imaging, others will step in and do it, and they will then inevitably take over the clinical practice in the areas of that research. We pleaded the case for financial support of academic radiology department research programs by the private practice community. We also pointed out that academic radiology has to take certain steps of its own to promote research and thereby help assure the integrity of the field. In this article, we discuss some of those steps that need to be taken.

(1) Significant changes must be made in the way radiology residents are trainedOthers have also recently stressed the importance of this [2-4]. Currently, most radiology residents undergo 6 years of training - a clinical internship (often transitional), followed by 4 years of radiology residency, then followed by an optional 1-year subspecialty fellowship. The rate at which graduating residents take fellowships seems related to the job market. When private groups are actively recruiting and salary offers are lucrative, many residents opt to go straight into practice without a fellowship. When the job market slows down, residents realize they need to have subspecialty expertise to make themselves more marketable, and so more of them take fellowships. We believe that subspecialty expertise is important for all radiologists, if they are to help provide high quality 
patient care by being able to give informed and expert interpretations of imaging studies to their colleagues in other medical specialties.

As things stand now, the clinical internship is largely a waste of time, as it usually has no bearing on what subspecialty the radiology resident will pursue in the future. In addition, the 4th year of residency is now largely focused upon preparation for the oral examination of the American Board of Radiology (ABR). Thus, it too is largely a waste of time in terms of useful training for future practice.

The model we strongly recommend is along the lines proposed by Arenson and Dunnick [2]. The clinical internship would be done away with and the residency would commence immediately after graduation from medical school. The residency would be 5 years and would consist of a core curriculum of 3 years, followed by a required subspecialty advanced training period (ATP) of 2 years. The 3 -year core curriculum would provide basic training in all aspects of radiology but would not attempt to make the trainee an expert in every imaging subspecialty. As Arenson and Dunnick point out, radiology has become so broad and complex that no one can be considered an expert in the entire field. The 2-year required ATP would include subspecialty radiology training, rotations on the clinical services related to that imaging subspecialty, and research training. As an example, a 2-year ATP could be comprised of 15 months of subspecialty radiology, 6 months of clinical rotations on related services, and 3 months of research. During the 3 months of research, 1 day per week of subspecialty radiology practice could be incorporated. When combined with approximately 3 months of training the resident 
would receive in his/her area of interest during the core curriculum, that individual would end up with over 1.5 years of subspecialty radiology training upon completion of the 5year program.

The 2-year ATP could replace some fellowships but would not necessarily have to do so. Those departments currently offering fellowship programs that are accredited by the Accreditation Council for Graduate Medical Education could continue to do so. Residents wanting additional subspecialty training or those wanting to add a second subspecialty could continue to take them. The additional fellowship year could be tailored to the wishes of the sponsoring department, and could be totally devoted to subspecialty imaging training, or could include varying periods of research or rotations on related clinical services.

Would our proposed 5-year program be feasible or acceptable to the ABR? It would seem so. The ABR has already approved the Holman research pathway $[4,5]$ and a specialized interventional radiology track [4]. These 2 pathways provide radiology core curricula of, respectively, 27 and 32 months.

The major advantages of what we and Arenson and Dunnick have proposed are that: (a) every radiology resident would complete training with subspecialty expertise in at least one major area of the field, and (b) every resident would have some training in research. We cannot overemphasize the importance of the latter. If academic radiology departments don't provide research training to their residents, they can hardly expect 
those residents to show much enthusiasm for an academic career in which knowledge of research methodology is crucial.

(2) Change the timing of the oral ABR board examinations - This is also been suggested by others $[2,6,7,8]$ but nothing has happened yet. Radiology is currently the only medical specialty in which the final board examination is given during residency [2, $7,8]$. The result has been that residents in most academic departments waste much or all of their $4^{\text {th }}$ year consumed by "boards mania". We propose that the oral ABR examination be postponed until 2 years after completion of all training. This would have several beneficial effects on the field and especially on radiology research. First, residents would spend their final years of training learning to practice radiology at the highest subspecialty levels, instead of trying to learn answers to anticipated board questions. As pointed out by Grossman and McGuinness [8], this enhances the value of radiologists to specialist clinicians and helps quell the arguments of those who might try to encroach upon the practice of imaging. Second, they could assume a larger role in supervising and teaching their junior colleagues. This would free up some time of faculty members, who could then devote that time to research. Third, the senior residents would be better able to concentrate on learning research methodology and doing research themselves. Fourth, some residents would likely decide to spend those first two post-residency years in academic radiology departments, where they could continue to refresh their knowledge of all aspects of radiology prior to the board examinations. This would help academic radiology departments recruit junior faculty. These junior faculty would be capable of 
doing research, and hopefully some of them would enjoy the experience enough to want to stay in academics permanently.

(3) The leading research radiology departments should band together and require that all their residents undergo serious research training - This could be either along the lines of the Holman pathway [4] or perhaps by adding one more year of research to the 2year ATP outlined above. It has been pointed out $[9,10]$ that $50 \%$ of all NIH grant funding to academic radiology goes to just 8 departments, and that the next $30 \%$ goes to another 13. With graduating medical students beating down the doors to get into radiology residencies, these 21 elite research departments can afford to be very choosy. If they all as a group required their residents to train in and perform research, perhaps they might lose a few candidates who weren't interested in research, but so what? Without any question, they could still easily fill their programs, and their trainees would be people who were interested in research and had some motivation to do it. As recounted by Baum [9], this is exactly what took place among the leading academic departments of surgery in the country, and the results have been that surgical research has improved and that most residents coming out of those programs end up in academic careers.

Since Medicare does not pay for research time for residents, funding of that research time could be a problem. Some funding could come from existing research grants already in the departments, or from department endowments or research funds, or perhaps from support provided by private practice radiology groups [1]. 
What about the other 168 or so academic radiology departments that are not in the top 21? They too would need to provide research training and experience under the 5-year program we suggested above. That could be less in the form of basic imaging research, but more in the way of hypothesis-driven clinical or translational research. As an example, in our department at Thomas Jefferson University Hospital, every $2^{\text {nd }}$ year resident must complete a project which is then presented at a departmental research conference and submitted for presentation at a major radiology meeting. The residents are mentored by faculty members who have expertise in research methods, and the methodology is critiqued at the departmental research conference. It has proven to be a good experience which has generated interest in research among both trainees and faculty, although it is still too early to tell whether this will pay off in greater long term interest among our residents in academic careers.

(4) Emphasize that internally funded clinical and translational research (not just NIH-funded research) can be very valuable - Within the leading academic radiology departments, there is perhaps a bit too much emphasis placed on NIH funding. These departments often compete for bragging rights to being in the top ten or fifteen in NIH funding. While NIH funding is certainly very important, most research papers in leading radiology and other medical journals do not cite NIH funding. For example, most recent research in advanced cardiac imaging (arguably the most important new growth area in radiology) has come either from the manufacturers or internally funded groups of investigators in academic radiology departments[1]. 
Obtaining NIH funding can be a time-consuming and intimidating process, often with plenty of discouragement along the way. If graduating residents who are contemplating academic careers are led to believe that they can only succeed through obtaining NIH funding, they could be deterred from choosing academics. Academic departments might be well advised to place less emphasis on NIH funding and instead point out that there are other ways to conduct good research. Funding can be obtained from other sources foundations, radiology societies, philanthropy, and industry. Academic radiologists can participate in NIH-sponsored clinical trials through an organization like the American College of Radiology Imaging Network (ACRIN) without being principal investigators on those trials. And finally, many academic radiology departments fund research internally by giving faculty members protected research time each week.

\section{The role of the Society of Chairmen Of Academic Radiology Departments}

(SCARD ) - Who will provide the leadership necessary to accomplish the aforementioned changes? The answer to that is SCARD. Unfortunately SCARD has been a rather passive and indecisive organization throughout the decades of its existence (both authors are SCARD members and one -DCL - is a past president). Despite the fact that the organization consists of the senior leadership of the academic radiology world, it has remained silent on most of the major issues confronting academic radiology and has let other voices predominate. This is because of the loose structure in which SCARD is organized. No good mechanism exists through which SCARD can take a position and then pursue it to a conclusion. SCARD has its major meeting each fall, and it also has a more abbreviated meeting each spring at the annual meeting of the Association of 
University Radiologists. The SCARD fall meeting consists of (a) a structured program featuring presentations by selected speakers on various topics, and (b) a business luncheon, at which time certain issues of concern to the membership can be briefly discussed and debated. As might be expected, it is rare to have unanimity of opinion on these issues, and this seems to result in organizational paralysis. If not everyone agrees with a proposed solution to a problem, the tendency has been to either procrastinate or drop the matter entirely.

We believe the SCARD meetings need to become less structured with fewer formal presentations. Instead, a small number of pressing issues should be put on the agenda. Several speakers could present the various pros and cons and then there should be an extended debate among the membership. Votes should be taken and a SCARD position should be adopted if a certain percentage of the membership - say $75 \%$ - agrees. That position should then be vigorously pursued. Some of the ideas we have proposed herein, such as changing the structure of the residency program and the timing of the oral board examinations, will obviously be controversial. SCARD should discuss these matters in depth, take a position, and then exert leadership in getting that position adopted. If it comes down in favor of these or similar proposals, contact with the appropriate bodies (such as the ABR, the Radiology Residency Review Committee, Medicare, and the American Board of Medical Specialties), needs to be initiated and plans need to be made to implement the changes. SCARD must become proactive and establish itself as the leading organization in making policy for academic radiology. 
of course requires financial support, and academic radiology departments must find new and better ways to bring in revenue. Traditionally, academic radiology departments have been hospital-based and have depended upon professional component fees as their primary revenue source. Meanwhile, they are in competition with private radiology groups who own their imaging equipment, derive profit from it, and can therefore afford to pay much higher incomes to their members. Needless to say, this is one important reason why graduating residents may be attracted to private practice at the expense of an academic career. Academic radiology departments should develop their own outpatient imaging centers, either by themselves or through joint ventures with their hospitals and/or imaging center companies. Our department did this in 2002 and it has become an important source of revenue and a valuable aspect of our practice. Despite the reduction in technical component payments for outpatient imaging centers that came with the Deficit Reduction Act of 2005, it is still possible for radiology departments that have a large referral base and that can practice efficiently to derive profit from an outpatient center. There are of course other ways for academic departments to become more entrepreneurial, but that is beyond the scope of this article.

In conclusion, we have proposed some major changes which are sure to be controversial, and we have suggested that SCARD must assume the leadership role in getting these changes implemented. We believe such changes are vital in the interest of improving research capability throughout the academic radiology community. More and better research by radiologists will unquestionably help them preserve the scope of their 
practice. And at the same time, these changes will ensure thorough subspecialty training of all radiology residents and promote high quality radiologic care for patients. 


\section{References}

1. Levin DC, Rao VM. Turf wars in radiology: The future of radiology depends on research - and on your support of it! J Am Coll Radiol, in press.

2. Arenson R, Dunnick NR. Training a better radiologist. J Am Coll Radiol 2006; 3:389393.

3. Jost GR, Changing the curriculum. RSNA News 2006; 16: 4.

4. Lee RK. The case for the three-year residency. J Am Coll Radiol 2004; 1: 992-996.

5. American Board of Radiology. Holman research pathway, Available at:

http://www.theabr.org/Holman.htm. Accessed January 1, 2007.

6. Iafrate G, Kaye A. Timing of the oral radiology boards. J Am Coll Radiol 2004; 1: $527-528$

7. Cohen MD, Gunderman RB, Frank MS, Williamson KB. Challenges facing radiology educators. J Am Coll Radiol 2005; 2: 681-687.

8. Grossman RI, McGuinness G. The three and one-half year radiology residency. Am J Neuroradiol 2006; 27: 1803.

9. Baum S. What can we learn from success? Acad Radiol 2006; 13: 1449-1452

10. Thrall JH. Building research programs in diagnostic radiology. Part 1. Framing the issues. Radiology 2006; 241: 646-650. 
